\title{
Year-class strength and growth rate in young Atlantic cod Gadus morhua
}

\author{
Steven E. Campana* \\ Marine Fish Division, Bedford Institute of Oceanography, PO Box 1006, Dartmouth, Nova Scotia, Canada B2Y 4 A2
}

\begin{abstract}
The paradigm relating early life history growth rate to survival rate and/or year-class strength has remained largely untested among marine fishes. Using Atlantic cod Gadus morhua on Georges Bank (NW Atlantic) as a test species, I reconstructed the larval and juvenile growth sequences of 5 successive year-classes of cod and related them to 2 independent indices of year-class strength Larval and juvenile growth sequences reconstructed from the otolith microstructure of young-of-theyear juveniles differed significantly among year-classes. Temperature was a significant, but not necessarily a primary, source of the within-year and between-year variations in growth. Neither the larval growth sequence nor the hatch date distribution was correlated with year-class strength. However, otolith size at age and body size at age at the pelagic juvenile stage were both highly correlated with year-class strength. Differences in growth rates and associated exposure times to high larval mortality rates were sufficient to account for much of the 4 -fold difference in adult abundance among the yearclasses.
\end{abstract}

KEY WORDS: Otolith - Daily growth increment - Year-class strength $\cdot$ Recruitment $\cdot$ Survival Growth rate

\section{INTRODUCTION}

Interannual fluctuations in the year-class strength of marine fish populations are often evident by the end of the first year of life, suggesting that the key determinants of interannual survival variability occur during the early life history (Houde 1987). Covariation in the growth and survival rates of the young is often assumed to be a source of the variability in year-class strength, but direct evidence of the effect is lacking. According to the hypothesis linking growth and mortality rates in young fish (Shepherd \& Cushing 1981, Houde 1987, 1989, Miller et al, 1988, Rice et al. 1993, Cushing \& Horwood 1994), a survival advantage goes to fish growing quickly through a 'mortality window', a period of several months during which as much as $99.99 \%$ of a cohort may die. A rapid growth rate through the larval and juvenile stages is thought to increase the probability of survival due to an enhanced ability to feed and avoid predators (Rice et al. 1993, Cushing \& Horwood 1994). While widely accepted,

·E-mail: s_campana@bionet.bio.dfo.ca field evidence supporting this hypothesis for marine fishes has been elusive.

Cod spawn on Georges Bank (NW Atlantic) in late winter of each year, producing buoyant eggs and larvae which metamorphose into pelagic juveniles of about $17 \mathrm{~mm}$ length after 1 to 3 mo (Campana \& Hurley 1989). The pelagic juveniles feed in the water column until they reach a size of 30 to $40 \mathrm{~mm}$, at which point they begin a pratracted settlement to the ocean bottom (Lough \& Potter 1993). Using the otolith microstructure of juvenile Atlantic cod Gadus morhua from Georges Bank, I reconstructed the daily growth histories of the 1984-1988 year-classes and related them to 2 independent indices of survival through to the adult stage. Differences in growth trajectories among year-classes were subsequently used to calculate expected differences in exposure time to high larval mortality rates, and the associated impact on cohort abundance. These cohort abundance predictions were then compared with the differences in year-class strength which were actually observed. The objective of the study was to test the hypothesis that growth and survival rates in young marine fish are directly related. 
Table 1 Gadus morhua. Summary of sampling information for young-of-theyear cod. FL: fish length (mm)

\begin{tabular}{|ccccccc}
\hline Year & Date & $\begin{array}{c}\text { Latitude } \\
(\mathrm{N})\end{array}$ & $\begin{array}{c}\text { Longitude } \\
(\mathrm{W})\end{array}$ & $\begin{array}{c}\text { Mean FL } \\
\pm \mathrm{SE}\end{array}$ & $\begin{array}{c}\text { Mean age } \\
\pm \mathrm{SE}\end{array}$ & $\mathrm{n}$ \\
\hline 1984 & 12 June & $41^{\circ} 45^{\prime}$ & $66^{\circ} 58^{\prime}$ & $34.1 \pm 0.4$ & $80.3 \pm 1.3$ & 43 \\
1985 & 24-26 June & $41^{\circ} 45^{\prime}$ & $66^{\circ} 40^{\prime}$ & $43.7 \pm 1.1$ & $98.0 \pm 1.1$ & 69 \\
1986 & 20 June & $41^{\circ} 30^{\prime}$ & $66^{\circ} 50^{\prime}$ & $33.7 \pm 0.5$ & $95.4 \pm 1.0$ & 47 \\
1987 & 31 July & $42^{\circ} 05^{\prime}$ & $66^{\circ} 30^{\prime}$ & $60.1 \pm 1.2$ & $133.8 \pm 1.2$ & 32 \\
1988 & 20-27 June & $41^{\circ}-42^{\circ}$ & $66^{\circ} 69^{\circ}$ & $34.6 \pm 0.8$ & $96.9 \pm 2.4$ & 49 \\
\hline
\end{tabular}

\section{MATERIALS AND METHODS}

Georges Bank was selected as the study site in light of the relative abundance of young cod in the area and, in particular, the availability of 2 independent indices of cod survival through to the adult stage. Cohort survival is often difficult to measure, and this explains much of the reason for the relative absence of marine field studies on the growth-survival interaction. In this study, measures of year-class strength were taken from published estimates of abundance at age from research vessel (RV) surveys and virtual population analysis (VPA). U.S. RV surveys of age 1 and 2 cod conducted in the spring and fall of each year showed highly correlated abundance trends for each cohort (Hunt \& Buzeta 1995). Therefore, a single RV index was produced by taking the first principal component of the 4 survey time series. A second index of yearclass strength was the abundance at age 1 from a converged VPA (Hunt \& Buzeta 1995), lagged to the year of hatch. Since the VPA and RV indices were highly correlated through the study period $(r=0.95)$, the VPA results have been used as representative of year-class strength throughout this paper Estimates of spawning stock biomass were based on beginning-of-year VPA biomass, adjusted with age-maturity schedules (Hunt \& Buzeta 1995).

To reconstruct the growth history of the cod survivors from each of the 5 cohorts, random samples were taken of young-of-the-year (YOY) cod 25 to $75 \mathrm{~mm}$ in length in pelagic and bottom trawl surveys of northeastern Georges Bank in late June or July of each year (Table 1). Fish size at capture was comparable in all years except 1987, in which the later survey date resulted in the collection of significantly $(p<0.05)$ larger fish (Table 1). Since growth increments in the otoliths of young cod are known to form on a daily basis (Geffen 1995), counts and measurements of daily growth increments in the lapillar otoliths were used to provide accurate estimates of age, hatch date, daily otolith growth rate, otolith size at age, and otolith size at date for an average of 50 individuals per year-class (Campana 1989, 1992). Fish length corresponding to each estimate of otolith size was backcalculated using the biological intercept equation (Campana 1990). Hatch date distributions were not corrected for mortality effects, since all samples were collected in the low-mortality juvenile stage (Campana \& Jones 1992)

The daily temperature record of the water to which the young fish were exposed was reconstructed from temperature measurements taken on the northeastern cap of Georges Bank at depths between 30 and $50 \mathrm{~m}$. Since temperatures were not available for every day of the year, a cubic regression was fit to the available data between 1 January and the date corresponding to that of fish collection for each year. All regressions were based on more than 100 temperature measurements per year, and all produced highly s.gnificant results with no obvious patterns in the residuals. The daily temperature records reported in this paper represent the predicted temperatures from each year's regression model.

Growth trajectories by age and/or day-of-year (DOY) were produced for each individual fish based on the width of each daily increment in the growth sequence. While growth data were acquired over a broad range of ages and dates for certain years, statistical analyses were restricted to the age range 30 to $93 \mathrm{~d}$ and DOY 110 to 162 to insure comparable coverage across years. All conclusions presented in this paper were based on repeated-measures analysis of variance (RM-ANOVA) of the individual growth sequences, since repeated-measures analyses properly take into account the longitudinal nature of growth within an individual (Chambers \& Miller 1995). Univariate statistics are not appropriate for such analyses since the sequential growth increments of an individual are, by their very nature, autocorrelated and non-independent. However, for the purposes of presentation, mean growth trajectories within each year have been included.

\section{RESULTS AND DISCUSSION}

As independent indices of cohort survival, both the $\mathrm{RV}$ index and cohort analysis demonstrated the same interannual variability in adult abundance (a 4 -fold difference among the 5 years) characteristic of many cod stocks. Both indices were highly correlated through the study period $(r=0.95)$, and both showed very similar patterns across the 5 years (Fig. 1). Therefore, there is no reason to doubt the validity of these measures of cohort survival. 


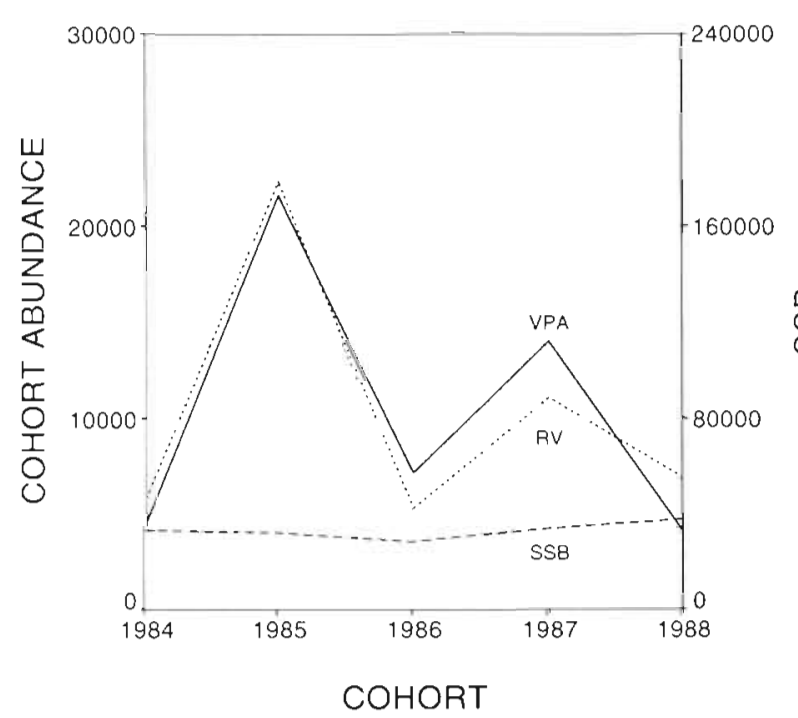

Fig. 1 Gadus morhua. Trends in cohort abundance and spawning stock biomass (SSB, in t) for Georges Bank cod through the $5 \mathrm{yr}$ study period. As independent measures of cohort abundance, the VPA numbers at age 1 ( $\times 10^{3}$ fish) and the first principal component of a scaled RV index show similar trends, although neither reflect SSB

The age-structured RV surveys demonstrated that year-class strength could sometimes be detected as early as the fall of the first year of life. However, yearclass strength was not evident at the egg stage: using spawning stock biomass as a proxy for egg production, no correlation between egg production and the abundance of the year-class was evident (Fig 1). Thus the relative abundance of the cohort was modified sometime between the time of egg production and the end of the first year of life.

The date of hatch played no obvious role in the probability of survival of the cohort. Hatch date distributions were remarkably similar among cohorts, with no significant differences in mean hatch dates (15 to 18 March) for the years 1985-88 inclusive (ANOVA, $p>0.60$ ) (Fig 2). Cod in 1984 were hatched significantly later than in the other years (ANOVA, $\mathrm{p}<0.05$ ), on a mean date of 24 March. Overall, however, hatch dates were not correlated with either YOY growth rates or year-class strength.

The daily growth rate of the otolith increased from about $1.5 \mu \mathrm{m} \mathrm{d}^{-1}$ in $30 \mathrm{~d}$ old larvae to about $4 \mathrm{\mu m} \mathrm{d}^{-1}$ in $93 \mathrm{~d}$ old juveniles, reflecting a general increase in growth rate with age. The individual growth rate trajectories differed relatively little within any given year, suggesting that individuals shared some common growth history (Fiq. 3). However, there were significant and substantial differences among cohorts (RMANOVA, $p<0.01$ ), with age, year and the age $x$ year interaction all significant as factors. Thus the daily


Fig. 2. Gadus morhua. Hatch date distributions (day of the year) for 5 cohorts of Georges Bank cod based on the otolith microstructure of YOY juveniles 


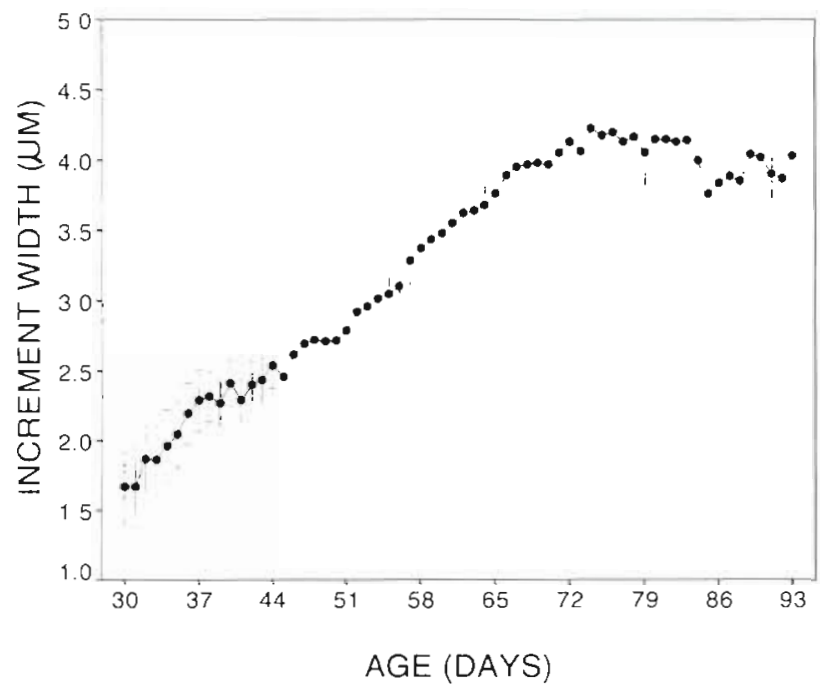

Fig. 3. Gadus morhua. Mean $( \pm 95 \%$ Cl) daily growth rate of otoliths trom the 1985 cohort of Georges Bank cod over an age range common to all 5 cohorts. The variances around the mean trajectories of the remaining cohorts were of similar magnitude to that shown here

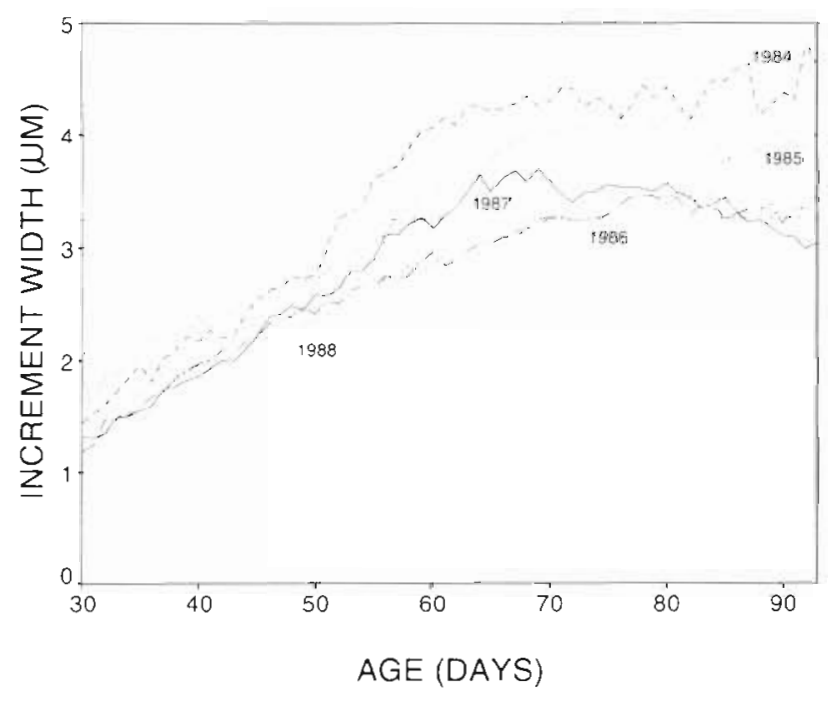

Fig. 4. Gadus morhua. Mean otolith growth rate trajectories for each of 5 cohorts of Georges Bank cod. All trajectories except those of 1986 and 1988 differed significantly from one another (RM-ANOVA, $p<0.05$ ). Increment widths for ages $>86 \mathrm{~d}$ in the 1984 cohort were based on 10 or fewer fish

growth rate trajectories differed across years, with the ranking among cohorts differing depending upon the age (Fig. 4). The median annual growth rate trajectories were not correlated with year-class strength. However, the daily temperature history differed substantially among years (Fig. 5), indicating very different temperature exposure histories for each cohort of cod. Indeed, when introduced as a covariate into the

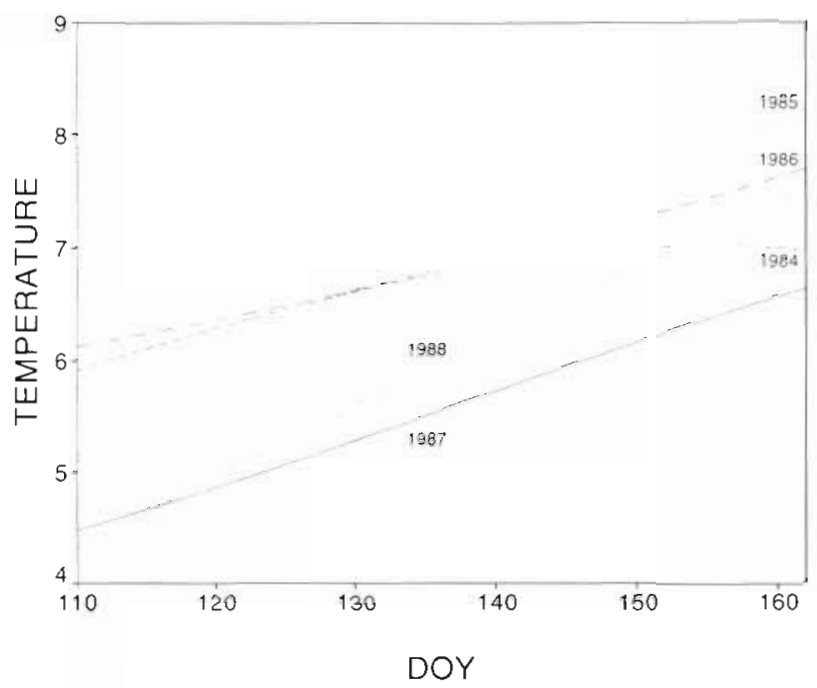

Fig. 5. Daily temperature $\left({ }^{\circ} \mathrm{C}\right)$ time series for waters of 30 to $50 \mathrm{~m}$ depth un the northeast cap of Georges Bank for the years 1984 to 1988 , reconstructed from non-daily measurements (see text)

repeated measures ANOVA model, temperature had a significant effect on otolith growth rate, both on a dayto-day basis and across years $(p<0.05)$. Nevertheless. temperature explained no more than $30 \%$ of the interannual difference in daily otolith growth rate, and thus could not be implicated as the sole, or even the primary, source of interannual difference in growth trajectory. Since a significant year effect persisted in the repeated measures model that included temperature, temperature must have operated in conjunction with other factors to produce the observed interannual differences in growth.

When integrated across ages, the trajectories of otolith size at age (Fig. 6) also differed significantly among cohorts (RM-ANOVA, $p<0.01$ ). From an age of about 55 d onward (corresponding to a fish size of 13 to $18 \mathrm{~mm}$ ), the relative size of the otolith of a cohort compared to that of other cohorts was fixed, with the exception of the 1984 cohort, whose interpretation was complicated by reduced numbers of older fish. Trajectories of fish size at age, derived from otolith backcalculation, showed very similar patterns. Thus, interannual differences in growth trajectories appeared to be largely fixed in the late larval or early juvenile stage of life.

If growth rate confers a survival advantage to young fish, it should be evident in a comparison among cohorts of widely differing survival rates (year-class strength). Both otolith and fish length at age during the pelagic juvenile stage were significantly correlated $(p<0.05)$ with cohort survival (Fig. 7), supporting the hypothesis of enhanced survival in fast-growing fish. The correlation was maximal at lengths greater than 


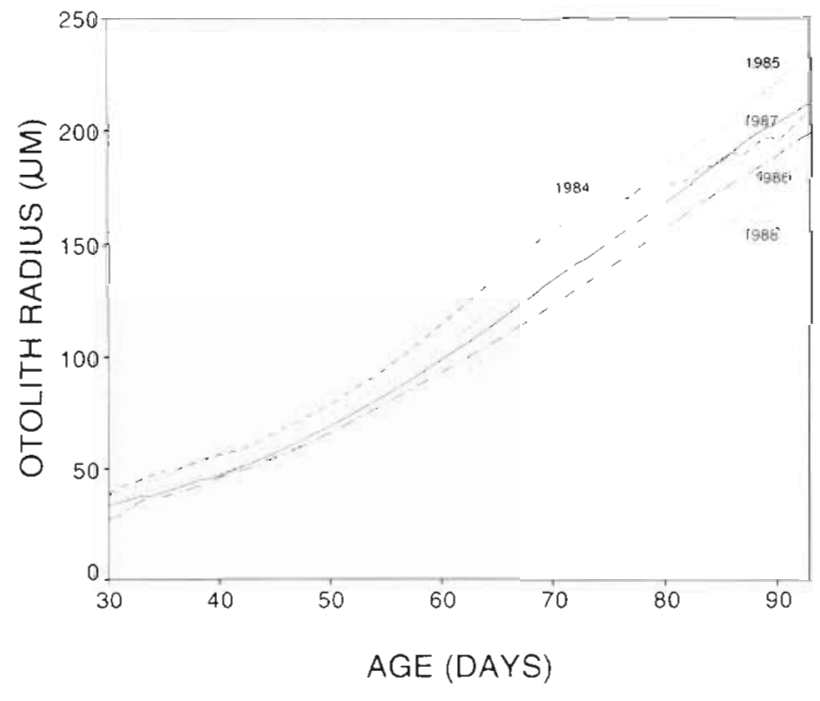

Fig. 6. Gadus morhua. Mean otolith growth trajectories of 5 cohorts of cod based on reconstruction from the daily growth sequence in the otolith. All trajectories difter significantly (RM-ANOVA, $\mathrm{p}<0.05$ ) from one another, and all except that of 1984 become fixed relative to other cohorts after the end of the larval stage (age $-55 \mathrm{~d}$ ). Reconstruction of ages $>86 \mathrm{~d}$ in the 1984 cohort was based on 10 or fewer fish

$30 \mathrm{~mm}$, near the size of transition from a pelagic to a bottom-dwelling habit (Lough \& Potter 1993). On the other hand, there was no significant correlation during the larval stage (ages $<40 \mathrm{~d}$ ), in keeping with suggestions that early larval stages may not play a significant

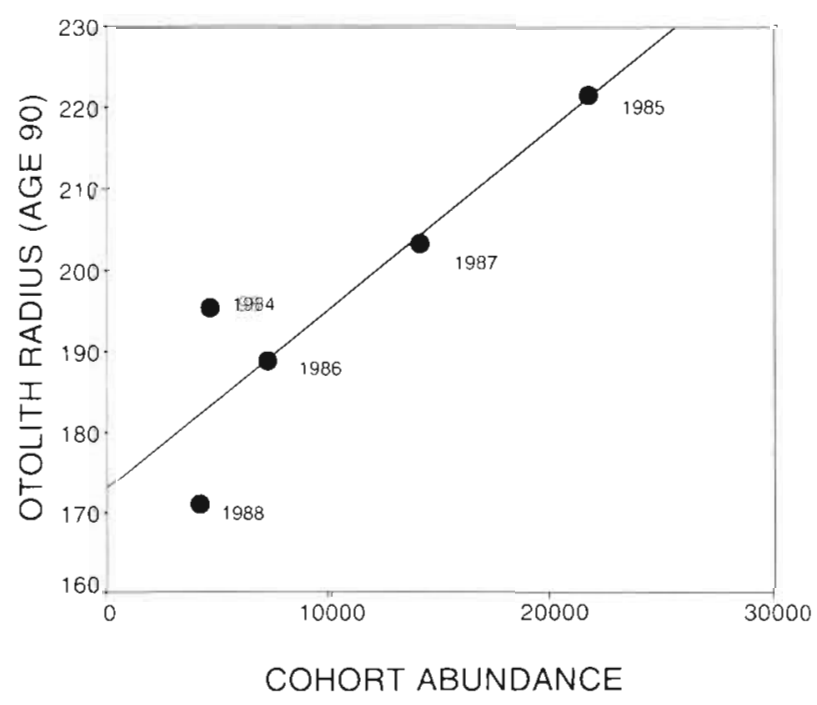

Fig. 7. Gadus morhua. Fitted regression $\left(r^{2}=0.80\right)$ between the mean otolith radius $(\mu \mathrm{m})$ at an age of $90 \mathrm{~d}$ and cohort abundance $\left(\times 10^{3} \mathrm{fish}\right)$ as measured trom $V \mathrm{PA}$. The regression supports the hypothesis that a more rapid growth rate through to the pelagic juvenile stage results in enhanced survival, and hence cohort abundance role in the determination of adult cohort abundance (Sissenwine 1984, Campana et al. 1989, Pepin 1993). Interannual differences in growth trajectories across DOY were relatively small and were uncorrelated with year-class strength, indicating that the observed relationship between growth and survival was a function of age, not of date. Therefare measurements of fish or otolith size at some fixed date in each year would not be expected to provide a useful index of year-class strength, thus explaining why fish length at the end of the first year of life (in March) was uncorrelated ( $p>$ $0.2)$ with year-class strength

The variability in instantaneous growth rates among cohorts was small (15\%) compared to that of adult cohort abundance $(400 \%)$ over the same period. To determine if the range in growth rates was sufficient to account for the observed pattern of survival, I estimated the difference in cumulative mortality which would accrue to each cohort due simply to growthrelated variations in the time required to reach the approximate length of settlement (about $36 \mathrm{~mm}$ ). Estimated times differed by only $14 \mathrm{~d}$ (with a mean of $93 \mathrm{~d}$ ) among cohorts. Nevertheless, given high mortality rates characteristic of the early life stages of cod (0.1 $\mathrm{d}^{-1}$; Houde 1987, Campana et al. 1989, Sundby et al. 1989), and assuming a constant instantaneous mortality rate, the effect on the range of cumulative mortalities was nearly 4 -fold. Egg production adjusted for the cumulative mortality difference among years reflected adult cohort abundance rather closely (Fig. 8),

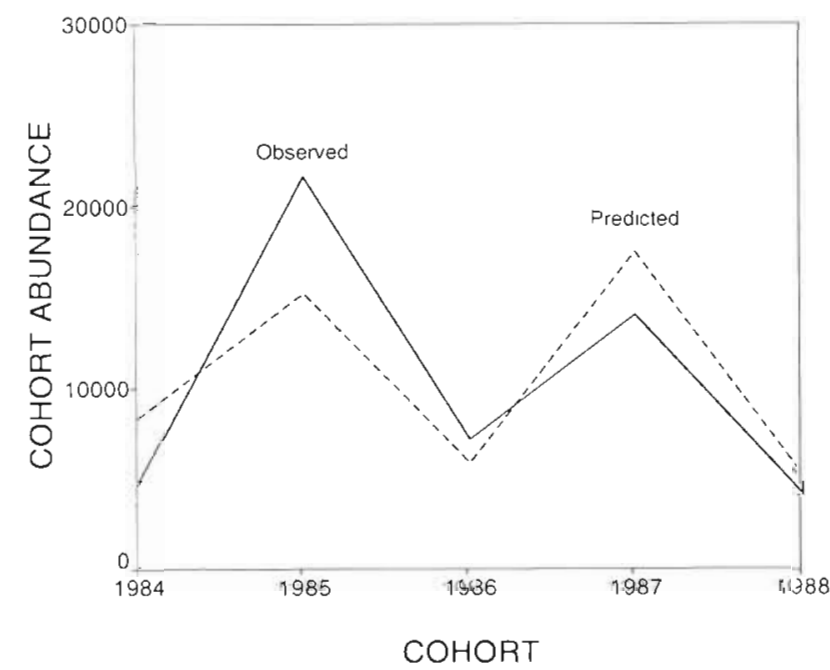

Fig. 8. Gadus morhua. Correspondence between observed cohort abundance $\left(\times 10^{3}\right.$ fish) from VPA and that predicted from spawning stock biomass after adjusting for growthrelated interannuai differences in cumuiarive moriaiily in ihte larval and juvenile stages. The correspondence is significant $(p<0.05)$, while that with unadjusted spawning stock biomass (Fig. 1) is not 
while unadjusted egg production did not (Fig. 1) Minor variations to the assumed mortality rate did not alter these conclusions, although the actual mortality rate probably varied among years. Thus, for cod, Houde's (1987) suggestion that small variations in the growth rate of young fish can explain much of the variability in survival rate to the adult stage appears to be borne out.

This study suggests that much of the variability in the year-class strength of a fast-growing cod population may be explicable on the basis of small interannual variations in the growth rate of the young fish. In addition to providing some of the first field evidence in support of the growth-mortality hypothesis, this study indicates that it may now be possible to predict the relative abundance of a cohort of adult cod while it is still in its first year of life, through examination of the otolith microstructure of newly settled juveniles.

Acknowledgements. I thank K. Drinkwater, J Hamel, D. Jackson, J. Neilson, J. Simon, L. Taylor and S. Thorrold for their assistance and advice in this project. I also thank D. Cushing, K. Frank, A. Geffen, C. Jones, P. Pepin, M. Sinclair, I. Suthers, S. Thorrold and R. Thresher for having provided helpful comments on the manuscript.

\section{LITERATURE CITED}

Campana SE (1989) Otolith microstructure of three larval gadids in the Gulf of Maine, with inferences on early life history. Can J Zool 67:1401-1410

Campana SE (1990) How reliable are growth backcalculations based on otoliths? Can J Fish Aquat Sci 47 2219-2227

Campana SE (1992) Measurement and interpretation of the microstructure of fish otoliths. In: Stevenson DK, Campana SE (eds) Otolith microstructure examination and analysis Can Spec Publ Fish Aquat Sci 117:59-71

Campana SE, Frank KT, Hurley PCF, Koeller PA, Page FH. Smith PC (1989) Survival and abundance of young Atlantic cod (Gadus morhua) and haddock (Melanogrammus aeglefinus) as indicators of yearclass strength. Can $J$ Fish Aquat Sci 46(Suppl 1):171-182

Campana SE, Hurley PCF (1989) An age- and temperaturemediated growth model for cod (Gadus morhua) and had-

This article was submitted to the editor dock (Melanogrammus aeglefinus) larvae in the Gulf of Maine. Can J Fish Aquat Sci 46:603-613

Campana SE, Jones CM (1992) Analysis of otolith microstructure data. In: Stevenson DK, Campana SE (eds) Otolith microstructure examination and analysis. Can Spec Publ Fish Aquat Sci 117:73-100

Chambers RC. Miller TJ (1995) Evaluating fish growth by means of otolith increment analysis: special properties of individual-level longitudinal data. In: Secor DH, Dean JM, Campana SE (eds) Recent developments in fish otolith research. University of South Carolina Press, Columbia, p 155-175

Cushing DH, Horwood JW (1994) The growth and death of fish larvae. J Plankton Res 16:291-300

Geffen AJ (1995) Growth and otolith microstructure of cod (Gadus morhual larvae. J Plankton Res 17:783-800

Houde ED (1987) Fish early lifo dvnamics and recruitment variability. Am Fish Soc Symp 2:17-29

Houde ED (1989) Subtleties and episodes in the early life of fishes. J Fish Biol 35(Suppl A):29-38

Hunt JJ, MI Buzeta (1995) Biological update of Georges Bank cod in unit areas 5Zj,m for 1978-94. DFO Atl Fish Res Doc $95 / 5$

Lough RG, Potter DC (1993) Vertical distribution patterns and diel migrations of larval and juvenile haddock Melanogrammus aeglefinus and Atlantic cod Gadus morhua on Georges Bank. Fish BuIl US 91:281-303

Miller TJ, Crowder LB, Rice JA, Marschall EA (1988) Larval size and recruitment mechanisms in fishes: toward a conceptual framework. Can J Fish Aquat Sci 45:1657-1670

Pepin P (1993) Application of empirical size-dependent models of larval fish vital rates to the study of production: accuracy and association with adult stock dynamics in a comparison among species. Can J Fish Aquat Sci 50:53-59

Rice JA, Muller TJ, Rose KA, Crowder LB, Marschall EA, Trebitz AS, DeAngelis DL (1993) Growth rate variation and larval survival: inferences from an individual-based size-dependent predation model. Can J Fish Aquat Sci 50:133-142

Shepherd JG, Cushing DH (1981) A mechanism for densitydependent survival of larval fish as the basis of a stockrecruitment relationship. J Cons Int. Explor Mer 39: $160-167$

Sissenwine MP (1984) Why do fish populations vary? In: May RM (ed) Exploitation of marne communities. Dahlem Konferenzen, New York, p 59-94

Sundby S, Bjorke H, Soldal AV, Olsen S (1989) Mortality rates during the early life stages and year class strength of northeast Arctic cod (Gadus morhua). Rapp PV Réun Cons Int Explor Mer 191:351-358

Manuscript first received: September 13, 1995

Revised version accepted: December 7, 1995 